\title{
Moral Reasoning in Sport: Validation of the Portuguese Version of the RSBH Value-Judgement Inventory in Adolescents
}

\author{
Luis CALMEIRO ${ }^{1} \bullet$ Sharon K. STOLL ${ }^{2}$ \\ Paul DAVIS 3
}

\begin{abstract}
7 he purpose of this study was to examine the validity and reliability of the Portuguese version of the Rudd Stoll Beller Hahm Valuejudgement Inventory (RSBHVI) in a sample of adolescents. The RSBHVI, which measures moral and social reasoning, was translated using a back translation method. A sample of $23810^{\text {th }}$ to $12^{\text {th }}$ grade high school students (age mean value 16.93 years, $s=1.34$ ) completed the Portuguese versions of RSBH, and the Task and Ego-orientation Questionnaire. Partial support for the original structure of the moral reasoning scale, but not the social reasoning scale, was found. Females, and non-athletes and individual sport athletes scored significantly higher than males and team sport athletes in moral reasoning, respectively. Moral reasoning was negatively correlated with ego-orientation $(r=-30 ; p<$. 001) and uncorrelated with task-orientation $(r=$ $.10, \mathrm{p}>.05)$. Participants who were low-ego scored higher in moral reasoning than those who were high-ego. It is suggested that decreasing levels of egoorientation may be necessary to improve athletes' moral reasoning.
\end{abstract}

Keywords: adolescents, character, moral atmosphere, moral behaviour, moral reasoning, sport

\footnotetext{
${ }^{1}$ School of Social and Health Sciences, Abertay University, Dundee, UK

2 Center for Ethics, University of Idaho, Moscow, ID, USA

${ }^{3}$ University of Sunderland, UK
} 


\section{Introduction}

The notion that sport involvement builds character is not uncommon. The concept of character is multifaceted (Jones and McNamee, 2000) and constitutes "the overall form and structure of human personality" (Flanagan, 1991, p. 181). Flanagan notes that we think of persons "as integrated systems of intentional states, dispositions and cognitive capacities" (p. 276), which represents character's constituents. Despite some of its more stern connotations, character does not entail that its constituents are invulnerable to contextual influence. The honest person can remain just that after yielding to an uncommonly tempting inducement to dishonesty. The logic of intentional states, dispositions and cognitive capacities demands, for sure, a robust endurance and reliability of character. The person, for instance, whose courage seems a hit or miss affair does not possess the virtue of courage. However, the endurance and reliability of an authentic character trait is usually less than total and it is contingent upon qualities such as learning histories or the broader economy.

Moral reasoning is often an indicator a person's character. Moral reasoning is usefully conceived as reasoning that contains at least one moral premise (e.g. 'It is wrong to punish the innocent') and aims at a moral conclusion (e.g. 'It is wrong to punish John'). Moral reasoning must preserve the reason-making features of reasoning about any topic and it must enclose a distinctively moral content.

The study of moral reasoning has been deeply influenced by the work of Kohlberg (1984). Kohlberg conceived three levels of moral reasoning: preconventional, conventional and post-conventional. The pre-conventional level is common in young children, typical of those individuals for whom norms and social expectations are entities that reside externally to the self. Reasoning is guided by a set of fixed rules that require obedience in order to avoid punishment or is guided to fulfil tangible and specific individual needs. In the conventional level the concepts of justice or injustice are not bound by consequences or punishment but by conformity to existing social and moral norms. Such reasoning results from internalized norms and social expectations, reflective of what is expected of individuals for social approval purposes, or from a belief in the maintenance of order and law, based on shared and socially accepted codes of conduct. At the post-conventional level, individuals operate beyond social conformity to consider universal ethical principles (e.g., justice, right to live, freedom). Norms are relative and therefore can be interpreted and transformed accordingly to guarantee observance of those ethical principles. Yet, such interpretation of norms although constructed at the individual level is in harmony with the social utility principle, that is, the establishment of a 
social contract focused on the common good. Principles of justice (e.g., "are my actions fair?"), universality (e.g., can my actions be applied to all situations?) and reversibility (e.g., would I do the same thing if in a different position?) are paramount and can become more important than the social utility principle.

\section{Moral reasoning in sport}

Researchers argue that the sport context has the potential to promote virtues and prosocial behaviours (Kleiber and Roberts, 1981; Rutten et al., 2007; Rutten et al., 2011). However, the sport experience can build character only if the environment is structured so that character building becomes a stated goal supported by all sport agents (Doty, 2006). Sport can provide valuable experiences through which character can be learned, but character building is not an inherited and automatic consequence of sport participation. Evidence appears to concur with this perspective. When compared to non-athletes, high school athletes (Beller and Stoll, 1995) and college athletes (Bredemeier and Shields, 1986; Rudd and Stoll, 2004) scored lower in moral reasoning. Furthermore, moral reasoning was negatively related to aggression in young children (Bredemeier, 1994) and continuous involvement in sport was associated with participants' legitimization of aggressive behaviour in competition (Conroy, Silva, Newcomer, Walker and Johnson, 2001; Visek and Watson, 2005).

A variety of factors (e.g., age, gender, type of sport) mediate the relationship between sport and morality. For example, Romand, Pantaleon and Cabagno (2009) reported that children (8-11 years old) rated a variety of behaviours in moral dilemmas as more "inappropriate" and were less likely to engage in such behaviours than adolescents and young adult athletes. Additionally, the use of instrumental transgression was significantly higher in adults compared with adolescents and adolescents compared with children.

Females engage in more mature moral reasoning than males (Beller and Stoll, 1995; Kavussanu and Roberts, 2001; Rudd and Stoll, 2004). Kavussanu and Roberts (2001) suggested that females are less influenced by an egocentric perspective characteristic of the traditionally male-dominated sport context.

Concerning the type of sport, Conroy et al. (2001) demonstrated that the legitimization of aggressive behaviour was more evident in contact sports than non-contact sports. Aggressive behaviours were perceived as more legitimate by athletes both in sport and non-sport situations irrespective of gender (Gardner and Janelle, 2002). Participation in team sports was also associated with less mature moral reasoning compared with individual sports (Rudd and Stoll, 2004; Vallerand, Deshais and Cuerrier, 1997). 
The idea that moral lessons in sport are transferred to other domains in life does not appear to hold true. Jones and McNamee (2005) argue that moral reasoning and moral behaviour are context-related. People tend to tolerate behaviours within a sport context that would be unacceptable otherwise. Athletes rated a variety of behaviours in athletic situations as more legitimate than in other life-domains (Gardner and Janelle, 2002), suggesting that extended sport participation socialise athletes into accepting morally questionable behaviours. According to Bredemeier and Shields (1984), moral reasoning in sport tends to be more immature and egocentric than in other life situations because sport involves the pursuit of context-specific self-interest. Such "game reasoning" is thought to depend on the characteristic "moral atmosphere" of certain sports and populations (Jones and McNamee, 2000).

\section{Moral reasoning and goal orientations}

The study of moral reasoning in sport has often been conducted within an achievement goal framework (e.g., Boardley and Kavussanu, 2010; Kavussanu and Roberts, 2001). According to this framework, perceptions of competence depend on how individuals interpret success. For some individuals success results from learning new skills and exerting effort in the pursuit of mastery over challenging tasks. This perspective characterises "task-orientation" whereby success is self-referenced and competence is defined by one's ability to learn and improve. In contrast, other individuals feel competent when they outperform opponents or when they complete a task exerting less effort than others. This focus on winning and demonstrating superiority relative to others characterizes "ego-orientation." Because ego-orientated individuals are concerned with comparing favourably to others, it is more likely that they will engage in less mature moral reasoning and be less concerned with justice and fairness in the pursuit of their goals than task-orientated individuals (Kavussanu and Roberts, 2001). Kavussanu and Roberts (2001) found out that among college basketball athletes, ego-orientation was associated with the belief that intimidating opponents, faking an injury and risking injuring an opponent are acceptable behaviours. These athletes also reported higher intention to engage in such behaviours.

Results concerning task-orientation and moral reasoning are inconsistent. Kavussanu and Roberts (2001) and Stephens (2001) did not find any relationship between task-orientation and moral judgement, intention or behaviour. Taskorientation may have a neutral impact on moral variables for it may not translate instinctively into mature moral functioning (Kavussanu and Roberts, 2001). However, Dunn and Dunn (1999) reported that task-orientation was a positive predictor of sportsmanship among elite hockey players, while Duda, 
Olsin and Templin, (1991) and Stuntz and Weiss (2003) reported negative relationships between task-orientation and unsportsmanlike attitudes. Boardley and Kavussanu (2010) further reported that task-orientated athletes showed less antisocial behaviour towards opponents (e.g., attempting to intimidate and injure opponents). Concerning gender differences, Kavussanu and Roberts (2001) suggested that the more mature moral functioning of females result from stronger task-orientation and weaker ego-orientation when compared to males.

Rudd and Stoll (2004) reported the development of the Rudd Stoll Beller Hahm Value-Judgment Inventory (RSBHVI) to study moral reasoning in sport in a sample of college athletes. The RSBHVI is composed of two scales of 10 sport-specific scenarios each: (a) moral reasoning, based on the morally idealistic principles of honesty, responsibility, and justice, regardless of the existing social pressures in the sport; and (b) social reasoning, based on the social values of loyalty, teamwork, and self-sacrifice necessary for maintaining shared corporate ideals (Camire \& Trudel, 2010). Results indicated that non-athletes scored higher than team sport athletes on moral character whereas team sport athletes scored higher than non-athletes on the social character. Moreover, team sport athletes' social character scores were higher than their moral character scores. However, while the moral reasoning scale has been found to be valid and reliable, the social reasoning scale's reliability has not been confirmed, particularly in non-North American samples (e.g., Lai, Stoll, and Beller, 2006). These results might represent different weights attributed to the corporate values in different societies (Camire \& Trudel, 2010). Hence, the validation of these scales in different cultures is important.

The purpose of this study is to investigate the reliability and construct validity of the RSBHVI in a sample of Portuguese adolescents by examining scores of moral reasoning and social reasoning as a function of gender, sport participation, and goal orientation. It is expected that males and athletes will score lower in moral and social reasoning than females and non-athletes. It is also expected that ego-orientation is negatively associated to moral reasoning, while task-orientation is positively associated to moral reasoning. Finally, participants who are ego-orientated will score lower in social and moral reasoning than participants who are task-orientated.

\section{Methods}

\section{Sample}

The sample was composed of 238 secondary education students aged from 15 to 19 years $(\mathrm{M}=16.93 \pm 1.34 ; 36.6 \%$ males and $63.4 \%$ females $)$. One 
hundred and sixty one students did not participate in any form of organised sport (non-athletes), while 77 were athletes.

\section{Instruments}

Demographic information. Participants answered a short questionnaire concerning (1) gender, (2) type of sport participation $(1=$ non-athlete; $2=$ individual sport, $3=$ team sport, $4=$ both individual and team sports), and (3) for how many years have they played sports.

RSBH Value-judgement Inventory-Portuguese version. The Rudd Stoll Beller Hahm Value-Judgment Inventory (RSBHVI; Rudd, and Stoll, 2004) is a selfreport measure which assesses respondents' moral and social reasoning. The inventory is composed of 20 scenarios representing ethical dilemmas in sport. Both moral reasoning and social reasoning scales are the result of the sum of 10 scenarios to which subjects indicate on a 5-point Likert scale the extent of agreement with the presented solution $(1=$ strongly agree; $5=$ strongly disagree $)$. An example of an item measuring social reasoning is

"Miguel and Joao are long time tennis doubles partners. They have played hundreds of matches together. They are playing in the championship of a doubles tournament. After an exhausting match, they are only one point away from winning the match. Miguel calls the ball out that is clearly inside the line. With a guilty looking face, Miguel glances at Joao. As they are teammates, Joao should not overrule Miguel's line call."

An example of an item measuring moral reasoning is

"Football players are allowed to play the ball with any part of their body except the hands and outstretched arms. A football player receives a high pass with his chest and taps the ball to the ground with his hand. The referee does not see this action and the play goes on. As the referee's job is to see these actions, the player is not obliged to report the foul."

The RSBH Value-judgement Inventory was translated into Portuguese using a translation back translation method (Brislin, 1980).

Task- and Ego-orientation in Sport Questionaire (TEOSQ; Duda et al., 1994; Portuguese version [Fonseca and Biddle, 2001]). This questionnaire had been previously translated into Portuguese, and it is composed of two dimensions: 
ego-orientation and task-orientation. For the present study internal consistency was acceptable (ego-orientation, $\mathrm{a}=.87$; task-orientation, $\mathrm{a}=.71$ ).

\section{Procedure}

After the Centre for Ethics assurance that the present study complied with the University ethical policy for classroom settings, $10^{\text {th }}$ - to $12^{\text {th }}$ grade physical education teachers were contacted to explain the study and request access to students. When permission was granted, the first author attended the beginning of a class to explain the study to participants. Informed consent and parental consent forms were distributed to students. At the beginning of the following class, consent forms were collected and participants completed the TEOSQ followed by the RSBHVI. Participants were told that their answers were confidential and anonymous. The researcher was present at all times to clarify any doubts participants might have.

\section{Data analysis}

RSBH Value-judgement Inventory is composed of two existing questionnaires, representing moral reasoning and social reasoning; therefore, the underlying structure of each scale was verified separately using a principal component analysis (PCA) with a varimax rotation. A Principal component analysis was conducted on each scale of the RSBH Value-judgement Inventory. Two separate ANOVAS were conducted to determine differences in (a) gender and type of sport, and (b) sport participation and goal orientations. Where appropriate, Tukey HSD tests were used as post-hoc for significant ANOVAS. All significance values are reported at $\mathrm{p}<.05$.

\section{Results}

\section{Principal component analysis}

Table 1 represents the descriptive statistics, factor loadings and item-total statistics for the theoretically-driven unidimensional solution of the moral reasoning scale. 
Table 1

Mean, standard deviation and factor loadings (Principal Component Analysis, Varimax rotation), and item-total statistics for the Moral Reasoning items

\begin{tabular}{|c|c|c|c|c|c|}
\hline \multirow[b]{2}{*}{ Item } & \multirow[b]{2}{*}{ Mean $\pm s$} & \multicolumn{2}{|c|}{ Factor loadings } & \multicolumn{2}{|c|}{$\begin{array}{c}\text { Item-total statistics } \\
\text { (unidimensional solution) }\end{array}$} \\
\hline & & Factor 1 & Factor 2 & $\begin{array}{l}\text { Corrected Item- } \\
\text { total correlation }\end{array}$ & $\begin{array}{l}\text { Cronbach's alpha } \\
\text { if item deleted }\end{array}$ \\
\hline 16 & $2.26 \pm 1.07$ & .80 & & .50 & .74 \\
\hline 12 & $1.91 \pm 0.95$ & .75 & & .44 & .75 \\
\hline 19 & $2.69 \pm 1.68$ & .70 & & .54 & .73 \\
\hline 8 & $3.04 \pm 1.28$ & .59 & & .55 & .73 \\
\hline 14 & $3.05 \pm 1.28$ & .49 & & .46 & .75 \\
\hline 13 & $2.85 \pm 1.12$ & .46 & & .43 & .75 \\
\hline 17 & $3.34 \pm 1.51$ & .36 & & .43 & .75 \\
\hline 20 & $3.51 \pm 1.09$ & & .72 & .24 & .77 \\
\hline 18 & $3.19 \pm 1.16$ & & .61 & .41 & .75 \\
\hline 11 & $3.57 \pm 1.25$ & & .60 & .33 & .76 \\
\hline
\end{tabular}

Initial analysis retained 2 components that explained $46.1 \%$ of the variance. Three items did not load on the factor as predicted and therefore were removed from the scale. The final solution was composed of seven items with an internal consistency value of .73. Table 2 represents the descriptive statistics and factor loadings and the item-total statistics for the unidimensional solution of the social reasoning scale. 
Table 2

Mean, standard deviation and factor loadings (Principal Component Analysis, Varimax rotation) and item-total statistics for the Social Reasoning items

\begin{tabular}{|c|c|c|c|c|c|c|c|}
\hline \multirow[b]{2}{*}{ Item } & \multirow[b]{2}{*}{ Mean $\pm s$} & \multicolumn{4}{|c|}{ Factor loadings } & \multicolumn{2}{|c|}{$\begin{array}{c}\text { Item-total statistics } \\
\text { (unidimensional solution) }\end{array}$} \\
\hline & & Factor 1 & $\begin{array}{l}\text { Factor } \\
2\end{array}$ & $\begin{array}{l}\text { Factor } \\
3\end{array}$ & $\begin{array}{l}\text { Factor } \\
4\end{array}$ & $\begin{array}{l}\text { Corrected } \\
\text { Item-total } \\
\text { correlation }\end{array}$ & $\begin{array}{c}\text { Cronbach's } \\
\text { alpha if item } \\
\text { deleted }\end{array}$ \\
\hline 6 & $3.60 \pm 1.14$ & .68 & & & & .19 & .38 \\
\hline 2 & $2.66 \pm 1.06$ & .68 & & & & .28 & .35 \\
\hline 5 & $3.50 \pm 1.19$ & .64 & & & & .38 & .31 \\
\hline 7 & $4.53 \pm 0.76$ & & .84 & & & .20 & .38 \\
\hline 15 & $3.84 \pm 0.96$ & & .72 & & & .32 & .75 \\
\hline 4 & $2.84 \pm 1.14$ & & & .73 & & -.02 & .46 \\
\hline 9 & $3.16 \pm 1.20$ & & & -.61 & & .003 & .46 \\
\hline 1 & $3.66 \pm 1.20$ & & & .51 & & .03 & .45 \\
\hline 3 & $4.57 \pm 0.79$ & & & & .80 & .24 & .37 \\
\hline 10 & $2.70 \pm 1.07$ & & & & -.37 & 0.18 & .58 \\
\hline
\end{tabular}

Factor analysis did not support the unidimensional structure of the social reasoning scale. In addition, the item-total correlations were generally low which resulted in weak internal consistency $(\alpha=.42)$. Due to the lack of agreement with the theoretically-driven structure and poor internal consistency, this scale was removed from further analysis.

\section{Gender and sport participation differences in moral reasoning}

Table 3 presents participants descriptive statistics of moral reasoning as a function of gender and sport participation. Because five participants reported involvement in both individual and team sports, their data were remove from this analysis. 
Table 3

Mean and standard deviation for moral reasoning scores as a function of gender and sport participation

\begin{tabular}{|c|c|c|c|c|c|}
\hline & \multicolumn{2}{|c|}{ Gender } & \multicolumn{3}{|c|}{ Sport participation } \\
\hline & $\begin{array}{l}\text { Males } \\
(\mathrm{n}=84)\end{array}$ & $\begin{array}{l}\text { Females } \\
(\mathrm{n}=147)\end{array}$ & $\begin{array}{c}\text { Non-athletes } \\
(\mathrm{n}=159)\end{array}$ & $\begin{array}{l}\text { Individual sports } \\
\qquad(\mathrm{n}=14)\end{array}$ & $\begin{array}{l}\text { Team sports } \\
\quad(\mathrm{n}=58)\end{array}$ \\
\hline Mean & 15.65 & 21.15 & 20.60 & 19.14 & 15.17 \\
\hline S & \pm 4.84 & \pm 4.31 & \pm 4.52 & \pm 6.25 & \pm 4.75 \\
\hline
\end{tabular}

A 2 (gender) x 3 (type of sport) analysis of variance (ANOVA) was conducted to examine the effect of gender and type of sport in moral reasoning. There were significant main effects for gender $\left(F[1,227]=40.72, \mathrm{p}<.001, b^{2}=.152\right)$ and sport participation $\left(F[2,227]=13.51, \mathrm{p}<.001, h^{2}=.105\right)$. Concerning gender, females reported higher scores of moral reasoning than males. Concerning sport participation, Scheffe post hoc tests revealed that team sport athletes scored significantly lower in moral reasoning than individual sport athletes and nonathletes. No significant differences were found between individual sport athletes and non-athletes. Interactions between gender and sports participation was not statistically significant $\left(F[2,227]=2.37, \mathrm{p}>.001, h^{2}=.02\right)$.

\section{Relationship between moral reasoning and goal orientation}

Moral reasoning was negatively correlated with ego-orientation $(\mathrm{r}=-.29$, $\mathrm{p}<.001)$ but not associated with task-orientation $(\mathrm{r}=-.04, \mathrm{p}=.51)$. The association between ego-orientation and moral reasoning is stronger for males $(\mathrm{r}=-.34, \mathrm{p}<.001)$ than for females $(\mathrm{r}=-.18, \mathrm{p}<.05)$.

To examine differences of participants' moral reasoning as a function of goal orientations, participants were categorized as high/low task/ego orientation using the median split as the criteria for classification. A 2 × 4 ANOVA with sport participation (athlete vs. non-athlete) and the four combinations of goal orientations (high/low ego and high/low task orientations) as independent factors was conducted. For this analysis, the variable sport participation agglomerated all athletes due to the low cell size concerning individual sport athletes when the sample is broken down by goal orientation. Means values for each group are illustrated in figure 1. 


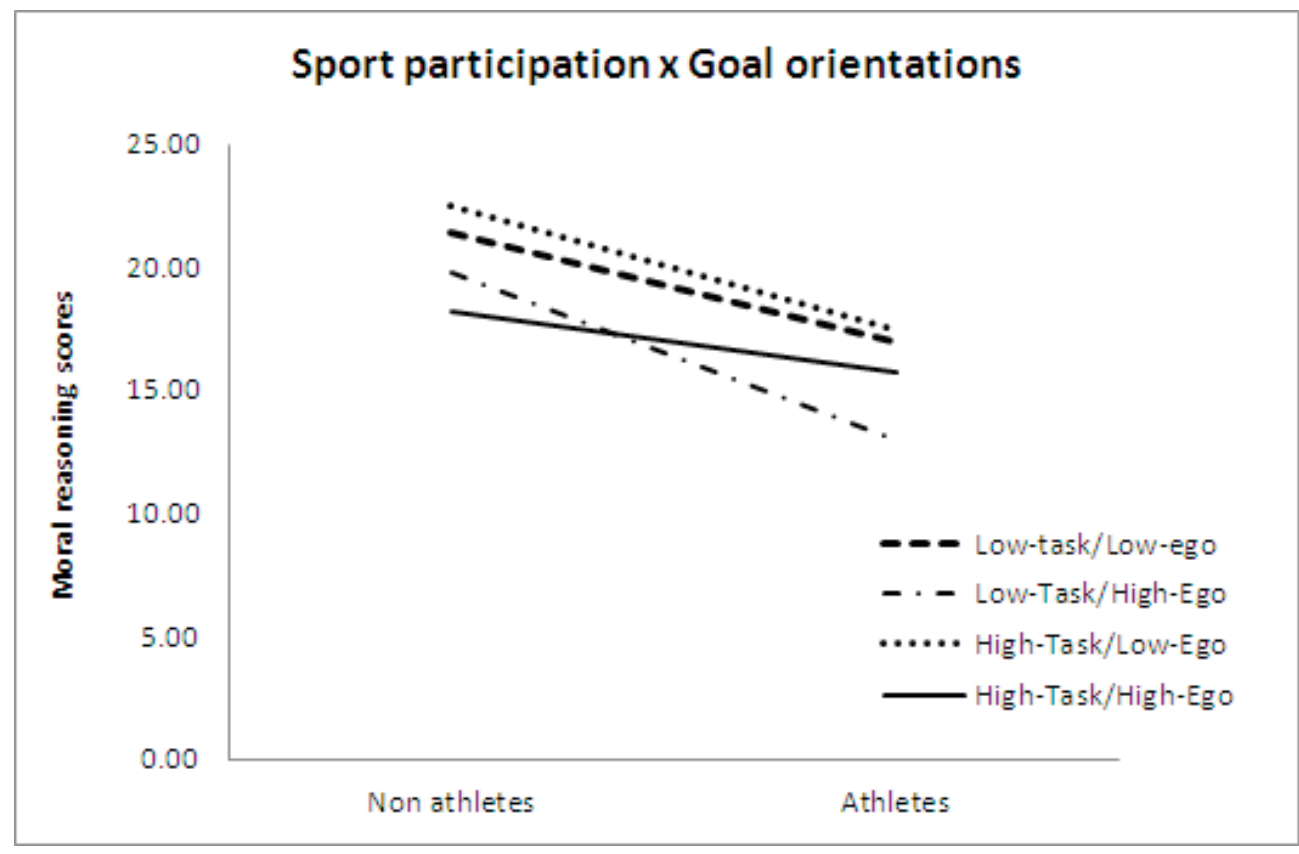

Figure 1. Moral reasoning scores as a function of sport participation and goal orientations

The ANOVA revealed a significant main effect for sport participation $\left(F[1,223]=50.06, \mathrm{p}<.001, h^{2}=.183\right)$, in which non-athletes $(\mathrm{M}=20.50 ; \mathrm{SD}=$ .73) reported higher scores of moral reasoning than athletes $(\mathrm{M}=15.58$; $\mathrm{SD}=$ $.47)$ as predicted. There was significant main effect for orientations $(F[3,223]=$ 6.79, $\left.\mathrm{p}<.001, h^{2}=.084\right)$.

Concerning goal orientation, Tukey HSD tests demonstrate that participants who were high-task/low-ego (mean $=20.71, \mathrm{~s}=5.57$ ) reported significantly higher moral reasoning scores than low-task $/$ high-ego $($ mean $=18.29, \mathrm{~s}=5.17$, $\mathrm{p}<.05)$ and high-task $/$ high-ego (mean $=17.10, \mathrm{~s}=5.13$ ) participants. Also, participants who were low-task/low-ego $($ mean $=20.42, \mathrm{~s}=4.20)$ reported higher moral reasoning scores than high-task/high-ego participants.

No significant interaction between sport participation and goal orientations was found $\left(F[1,223]=1.78, \mathrm{p}>.05, h^{2}=.023\right)$. Nevertheless, visual inspection of figure 1 indicates that non-athletes with high-task/high-ego orientation scored lower in moral reasoning, whereas as participants with low-task/high- 
ego scored lower in moral reasoning among athletes. For both athletes and nonathletes, low-ego orientation participants score the highest in moral reasoning.

\section{Discussion}

The purpose of this study was to examine the factorial validity of the RSBH Value-judgement Inventory in Portuguese adolescents. Factor analysis resulted in a 7-item moral reasoning scale and an inappropriate social reasoning scale. In support the moral reasoning scale's construct validity, females and non-athletes scored higher in moral reasoning than males and athletes, and moral reasoning was negatively associated to ego-orientation, but not to task-orientation.

\section{Factor structure}

Exploratory factor analysis of the moral reasoning scale yielded a shorter version that the original version, composed by 7 items. The factor structure of the social reasoning scale of the translated version strongly deviated from the structure of the original version. Lack of reliability of the social reasoning scale has been found in studies with non-North American samples (e.g., Lai, Stoll, and Beller, 2006). It is thought that in some cultures (e.g., Anglo-American Protestant) values taught in sport such as hard work, dedication, sacrifice, and loyalty might be given inflated prestige, and therefore undermine other equally important moral values (e.g. empathy, self-respect, individual flourishing). In addition, the distinction between moral values and social values at a philosophical level is disputable (Simon, 2000) rendering such separation of scales as unsuitable in culturally varied samples.

\section{Moral reasoning and gender}

As predicted, females significantly demonstrated higher moral reasoning than males (Beller and Stoll, 1995; Bredemeier and Shields, 1986; Duda et al., 1991; Hahm, Beller, and Stoll, 1989; Kavussanu and Roberts, 2001; Rudd and Stoll, 2004). It is argued that girls are less influenced by an egocentric perspective of competitive sport (Kavussanu and Roberts, 2001). Indeed, in the present study girls were significantly less ego-orientated than boys (mean $=17.24 \pm$ 5.49 for girls, mean $=19.46 \pm 5.39$, for boys, $t[178.22]=2.99, \mathrm{p}<.01)$. Females appear to be more sensitive than boys to what is "the right thing to do" from a justice and fairness point of view. In addition, as a male-dominated context, male adolescents may feel less compelled to abide by moral rules when competing in sport and may consider that deferment of these values is appropriate. This deferral of moral obligation to act in accordance to the principles of fairness and justice was labelled by Bredemeier (1995) as bracketed morality. 


\section{Moral reasoning and participation in sports}

As hypothesised, athletes demonstrated higher levels of moral reasoning than non-athletes. However, the significant differences found are between (1) team sports and individual sport athletes, and (2) team sport athletes and nonathletes.

The differences between team sport and individual sport athletes have been reported in the literature (Rudd and Stoll, 2004; Vallerand, Deshais and Cuerrier, 1997), and they may be explained by the phenomenon of "game reasoning" (Bredemeier and Shields, 1986), according to which transgressive acts in sport are acceptable because of its functional purpose of facilitating achievement of valued competitive outcomes (Silva, 1983). Game reasoning is likely to be a function of the moral atmosphere of the sporting context as it was more evident in sports such as basketball than swimming (Jones and McNamee, 2000). Because in team sports the direct interaction with the opponent largely determines success, there is more scope for engagement in strategies that focus not just on increasing one's performance but also in hindering the opponents' performance in more ways than morally accepted. In addition, it is possible that moral functioning is guided by a sense of team morality (Jones and McNamee, 2000) which can lead to moral disengagement, in which the fault for immoral behaviour rests with someone else (Boardley and Kavussanu, 2009). The weaker sense of team morality in individual sports may justify the lack of significant differences between individual sport athletes and non-athletes in this age group.

\section{Moral reasoning and goal orientations}

Concurrent with Kavussanu and Roberts (2001), the present study identifies a significant negative correlation between ego-orientation and moral reasoning. Ego-orientation had been shown to encourage antisocial behaviour towards opponents (Boardley and Kavussanu, 2010). Because ego-orientated individuals' main criteria of success are demonstrating superior ability compared to others, they are less likely to operate within the principles of fairness and justice (Nicholls, 1989). This association was stronger for males than for females probably due to males' higher egocentric interpretation of success in sport (Kavussanu and Roberts, 2001).

Contrary to prediction, task-orientation and moral reasoning were unrelated. Emphasis on self-improvement may steer athletes' efforts towards themselves or towards supporting teammates in achieving their goals, rather than focusing primarily on attempting any means to defeat opponents (Kavussanu and Roberts, 2001; Stephens, 2001). Such social and motivational attitude is likely to affect the within-team behaviour through increased encouragement and praise 
that reinforce ability and effort rather than (negative) behaviour directed at others. However, other studies support a relationship between task orientation and moral reasoning, in the form of respect for social conventions, rules and officials (but not respect for the opponent; Dunn and Causgrove Dunn, 1999) and unsportman-like attitudes (Duda et al., 1991). Hence, researchers need to identify the variables that might influence the relationship between taskorientation and moral reasoning.

The significant differences between goal-orientations indicate (a) that those who are high-task/low-ego orientated scored higher in moral reasoning than those who are high ego orientated (regardless of task orientation), and (b) those who are high-task/high-ego orientated scored lower in moral reasoning than those who are low ego-orientated (regardless of task orientation). In addition, those who are lower ego orientated scored higher in moral reasoning than those who are high ego-orientated regardless of their task-orientation. Overall, these results confirm the role of ego-orientation in regulating moral reasoning. In addition, in agreement to theoretical expectations, high ego-oriented individuals are more likely to be tempted to win at all costs whereas athletes with low egoorientation may be focused on "the right thing to do."

High task-orientation did not seem to have a protective effect on participants with high ego-orientation. It could be argued that when high-task/ high-ego individuals are unable to experience success based on normative criteria (e.g., defeat opponents), they might still value the opportunity to develop competence and seek self-improvement in selected self-referenced criteria (e.g., mastery goals). Nevertheless, visual inspection of the data indicate that moral reasoning scores in athletes with high-task/high-ego are higher than the scores of athletes with low-task/low-ego, while the opposite was observed for nonathletes; however, this apparent interaction was not statistically significant. Future research should explore whether or not high-task orientation can act as a safeguard to the "bracketed morality" (Bredemeier, 1995) likely to be evident in those with high ego-orientation.

Consistent with the current literature, the results of this study suggest that decreasing levels of ego-orientation may be necessary to improve athletes' moral reasoning. Hence, interventions that aim at structuring the learning environment to reduce the weight of normative feedback in defining success may improve moral reasoning. However, these results also suggest that increasing taskorientation appears to be insufficient to accomplish such aim. It is possible that task-orientation is related to increase prosocial behaviour (Boardley and kavussanu, 2009; Rutten et al., 2011) rather than reduction of anti-social behaviour. Hence, to continue to assess the validity of the Portuguese version 
of the RSBHVI, it is recommended to study athletes' prosocial and antisocial behaviours and to examine the role of the moral atmosphere in the prediction of moral reasoning.

\section{References}

Beller, J., \& Stoll, S. K. (1995). Moral reasoning of high-school student-athletes and general students: An empirical study versus personal testimony. Pediatric Exercise Science, 7, 352-363.

Bredemeier, B. J. (1994). Childrens' moral reasoning and their assertive, aggressive, and submissive tendencies in sport and daily-life. Journal of Sport and Exercise Psychology, 16, 1-14.

Bredemeier, B. J. (1995). Divergence in children's moral reasoning about issues in daily life and sport specific contexts. International Journal of Sport Psychology, 26, 453-463.

Bredemeier, B. J., \& Shields, D. L. (1984). Divergence in moral reasoning about sport and everyday life. Sociology of Sport Journal, 1, 48-357.

Bredemeier, B. J., \& Shields, D. L. (1986). Moral growth among athletes and nonathletes: A comparative analysis. Journal of Genetic Psychology, 14, 7-18.

Boardley, I. D., \& Kavussanu, M. (2009). The influence of social variables on moral disengagement on prosocial and antisocial behaviours in field hockey and netball. Journal of Sports Sciences, 27, 843-854.

Boardley, I. D., \& Kavussanu, M. (2010). Effects of goal orientation and perceived value of toughness on antisocial behaviour in soccer: The mediating role of moral disengagement. Journal of Sport and Exercise Psychology, 32, 176-192.

Camire, M., \& Trudel, P. (2010). High school athletes' perspectives on character development through spor participation. Physical Education and Sport Pedagogy, 15, 193-207.

Conroy, D. E., Silva, J. M., Newcomer, R. R., et al. (2001). Personal and participatory socializers of the perceived legitimacy of aggressive behaviour. Aggressive Behaviour, 27, 405-418.

Doty, J. (2006). Sports build character?! Journal of College and Character, 3, 1-9. 
Duda, J. L., Olson, L. K., \& Templin, T. J. (1991). The relationship of task and ego orientation to sportsmanship attitudes and the perceived legitimacy of injurious acts. Research Quarterly for Exercise and Sport, 62, 79-87.

Dunn, J. G. H., \& Dunn, J. C. (1999). Goal orientations, perceptions of aggression, and sportspersonship in elite male youth hockey players. The Sport Psychologist, $13,183-200$.

Dweck, C. S. (2000). Self-theories: Their role in motivation, personality, and development. Philadelphia, PA: Psychology Press

Flanagan, O. (1991). Varieties of Moral Personality. Cambridge: Harvard University Press.

Fonseca, A. M., \& Biddle, S. (2001). Estudo inicial para a adaptação do TEOSQ à realidade portuguesa: Questionário sobre a orientação para a tarefa e para o ego no Desporto (TEOSQp). In: Fonseca, A. M. (Ed.). A FCDEF-UP e a Psicologia do Desporto: Estudos sobre motivação [pp. 65-67]. Porto, Portugal: Editora da Universidade do Porto.Braga, Minho University Press.

Hahm, C. H., Beller, J. M., \& Stoll, S. K. (1989) The Hahm-Beller Values Choice Inventory. (Copyrighted). Available from Center for ETHICS*, University of Idaho, Moscow, ID.

Jones, C., \& McNamee, M. (2000). Moral reasoning, moral action, and the moral atmosphere of sport. Sport, Education and Society, 5, 131-146.

Kavussanu, M. (2006). Motivational predictors of prosocial and antisocial behaviour in football. Journal of Sport Sciences, 24, 575-588.

Kavussanu, M., \& Roberts, G. C. (2001). Moral functioning in sport: An achievement goal perspective. Journal of Sport and Exercise Psychology, 23, 37-54.

Kohlberg, L. (1984). Essays on moral development: Volume II. The psychology of moral development: The nature and validity of moral stages. San Francisco: Harper and Row.

Kleiber, D. A., \& Roberts, G. C. (1981). The effects of sport experience in the development of social character: A preliminary investigation. Journal of Sport and Exercise Psychology, 3, 114-122. 
Lai, S.-T., Stoll, S. K., \& Beller, J. M. (2006). An examination of moral and social values in Taiwanese college students. Research Quarterly for Exercise and Sport, 77, A-88.

Lumpkin, A., Stoll, S. K., \& Beller, J. M. (2003).Sport ethics: Applications for fair play. ( $3^{\text {rd }}$ edition). St. Louis, MO: McGraw Hill.

Nicholls, J. G. (1989). The competitive ethos and democratic education. Cambridge, MA: Harvard University Press.

Reall, M. J., Bailey, J. J., \& Stoll, S. K. (1998). Moral reasoning “on hold' during a competitive game. Journal of Business Ethics, 17, 1205-1210.

Rudd, A., Mullane, S., \& Stoll, S. (2010). Development of an instrument to measure the moral judgments of sport managers. Journal of Sport Management, 24, 59-83.

Rudd, A., \& Stoll, S. (2004). What type of character do athletes possess? An empirical examination of college athletes versus college non athletes with the RSBH Value Judgment Inventory. The Sport Journal, 7, 1-10.

Rutten, E., Stams, G., Biesta, G., et al. (2007). The contribution of organized youth sport to antisocial and prosocial bahavior in adolescents athletes. Journal of Youth and Adolescence, 36, 255-264.

Rutten, E., Schuengal, C., Dirks, E., et al. (2011). Predictors of antisocial and prosocial bahavior in an adolescents sport context. Social Development, 20, 294315.

Sage, L., \& Kavussanu, M. (2008). Goal orientation, motivational climate and prosocial and antisocial functioning in youth football: Exploring their temporal stability and reciprocal relationships. Journal of Sport Sciences, 26, 717732.

Silva, J. (1983). The perceived legitimacy of rule violating behaviour in sport. Journal of Sport Psychology, 5, 438-448.

Simon, R. L. (2000). Internalism and internal values in sport. Journal of the Philosophy of Sport, 27, 1-16.

Shafer-Landau, R. (2005) Moral realism: A defence. Oxford University Press. 
Stephens, D. E. (2001). Predictors of aggressive tendencies in girls' basketball: An examination of beginning and advanced participants in a summer skills camp. Research Quarterly for Exercise and Sport, 74, 421-435.

Stuntz, C. P., \& Weiss, M. R. (2003). Influence of social goal orientations and peers on unsportmanlike play. Research Quarterly for Exercise and Sport, 72, 257266.

Vallerand, R. J., Deshaies, P., \& Cuerrier, J. P. (1997). On the effects of the social context on behavioural intentions of sportsmanship. International Journal of Sport Psychology, 28, 26-140.

Visek, A., \& Watson, J. (2005). Ice hockey players' legitimacy of aggression and professionalization of attitudes. The Sport Psychologist, 19, 178-192.

Luis CALMEIRO, PhD, is a lecturer in Sport and Exercise Psychology at Abertay University, Scotland. He completed his Ph.D. in Educational Psychology with an emphasis in Sport Psychology at Florida State University, Tallahassee, Florida, USA. His dissertation, for which he received the Association for Applied Sport Psychology (AASP) Dissertation Award in 2007, focused on the link between cognition and emotion in influencing sport performance. Other research interests revolve around adolescents' psychosocial health and health behaviours, specifically physical activity and sedentary behavior patterns and the impact of the youth sport participation on wellbeing.

\section{Corresponding author:}

Luis Calmeiro

Department of Sport and Exercise Sciences

School of Social and Health Sciences, Abertay University

Kydd Building, Bell Street

Dundee DD1 1HG, UK

Phone: + 44 (0) 1382308498

E-mail: 1.calmeiro@abertay.ac.uk

Paul DAVIS, PhD is currently Senior Lecturer in the Sociology of Sport at the University of Sunderland, England, where he is in his sixth academic year. He is from a Philosophy background, and his thesis (University of Edinburgh) is on free will. He was Senior Lecturer in the Philosophy of Sport at the University of Wales Institute, Cardiff, 1996-2004. He has published regularly in the Journal of the Philosophy of Sport and Sport, Ethics and Philosophy, and was Review Editor of the former, 2002-2007. He is particularly interested in gender issues in sport, ethics and aesthetics in sport, and the mind in sport. He can be contacted at paul.davis@sunderland.ac.uk 
Sharon K. STOLL, PhD, the director of the Center for ETHICS* at the University of Idaho, is considered a leading authority in moral education intervention techniques for competitive adults and college aged students in America. Author of nine books including, Practical Ethics in Sport Management and Sport Ethics: Applications for Fair Play, with Lumpkin \& Beller. She has been featured on US TV "Night Line", "ESPN Sports Center", “ESPN Chat Line”, Fox Sports' “Goin' Deep”. In 2005, she was in over 50 major newspapers in US and abroad describing the Center's project working with the Atlanta Braves, and in 2006 she was the front page story for the Chronicle of Higher Education. In 2007 and 2013, she was featured in Sports Illustrated. In 2007 and again in 2012, she was one of the 100 Most Influential Sport Educators in the United States by the Institute for International Sport. She can be reached at: sstoll@uidaho.edu. 
